J. Electroanal. Chem. Short Communication Submitted: August 2014

\title{
CATHODIC REGENERATION OF A CLEAN AND ORDERED Cu(100)-(1×1) SURFACE FROM AN AIR-OXIDIZED AND DISORDERED ELECTRODE: AN OPERANDO STM STUDY
}

\author{
YOUN-GEUN KIM ${ }^{1}$ AND MANUEL P. SORIAGA ${ }^{1}$ \\ Joint Center for Artificial Photosynthesis \\ California Institute of Technology \\ Division of Chemistry and Chemical Engineering \\ Pasadena, CA 91125
}

${ }^{1}$ Corresponding authors. Email Addresses: msoriaga@caltech.edu.ygkim@caltech.edu. 


\begin{abstract}
In work related to the electrocatalysis of the $\mathrm{CO}_{2}$ reduction reactions, we recently reported in This Journal the structure and composition of a $\mathrm{Cu}(100)$ electrode surface, pre-dosed at low levels of $\mathrm{O}_{2(\mathrm{~g})}$ to simulate a $\mathrm{Cu}$ electrocatalyst unprotected from air, before and after immersion in alkaline electrolyte at fairly negative potentials to ascertain if an oxide-to-metal reduction reaction can be effected; experimental measurements were based upon ex situ techniques, lowenergy electron diffraction (LEED) and Auger electron spectroscopy (AES). It was found that the mildly oxided surface remained ordered and could be cathodically reduced back to a well-ordered oxide-free $\mathrm{Cu}(100)$; the quality of the LEED pattern and AES spectrum was less than ideal, however, due to small amounts of base electrolyte remnant in the emersed layer. In this Short Communication, we present results from operando electrochemical scanning tunneling microscopy (EC-STM) that not only confirm the earlier observations but, more importantly, depict more accurately the actual electrocatalysis conditions. An as-received commercially oriented $\mathrm{Cu}(100)$ disk that had not been protected from air was observed to consist of narrow terraces encrusted with highly disordered oxides. Cyclic voltammetry and coulometry showed that the oxidized surface consisted of five monolayers of $\mathrm{CuO}$ and quarter of a monolayer of $\mathrm{Cu}_{2} \mathrm{O}$. Upon complete cathodic reduction of the interfacial oxides, the surface was found to have reverted to a single-crystalline $\mathrm{Cu}(100)-(1 \times 1)$ structure. It may thus be inferred that, under the conditions of electrochemical $\mathrm{CO}_{2}$ reduction, the $\mathrm{Cu}$ catalyst would exist as a zerovalent metal.
\end{abstract}

\title{
KEYWORDS
}

Operando Electrochemical Scanning Tunneling Microscopy

Copper Electrocataysts for $\mathrm{CO}_{2}$ Reduction

Cathodic Regeneration of Ordered $\mathrm{Cu}(h k l)$ from Oxided Surfaces

Air-oxidized Copper Electrocatalyst Surfaces

In Situ Electrochemical Scanning Tunneling Microscopy 


\section{INTRODUCTION}

The electrochemical reduction of $\mathrm{CO}_{2}$ catalyzed by $\mathrm{Cu}$ is strongly influenced by the crystallographic orientation of the catalyst surface [1-3]: $\mathrm{Cu}(111)$ preferentially forms $\mathrm{CH}_{4}$, $\mathrm{Cu}(100)$ favors $\mathrm{C}_{2} \mathrm{H}_{4}$, and $\mathrm{Cu}(\mathrm{pc})$ may yield up to sixteen different products. However, unless the electrodes are prepared and maintained under a stringently oxygen-free environment, the copper surface would always contain several layers of oxide, $\mathrm{CuO}$ and/or $\mathrm{Cu}_{2} \mathrm{O}$, since the material is notorious for its high affinity towards gaseous oxygen [4,5]. It is of fundamental importance to understand how pure-copper electrocatalysis is enabled given the initial presence of an interfacial oxide crust.

In an earlier study published in This Journal [6], clean and highly ordered $\mathrm{Cu}(h k l)$ singlecrystal surfaces were exposed to low levels of $\mathrm{O}_{2(\mathrm{~g})}$, nominally fifteen minutes at $10^{-6}$ Torr, as a controlled means to simulate a $\mathrm{Cu}$ electrocatalyst unprotected from air [5]. The surfaces, which were only mildly oxidized and displayed ordered structures [e.g., $\mathrm{Cu}(100)-(\sqrt{2} \times \sqrt{2}) \mathrm{R} 45^{\circ}-\mathrm{O}$ and $\mathrm{Cu}(110)-(2 \times 1)-\mathrm{O}]$, were then immersed in alkaline solutions at fairly negative potentials. Ex situ surface interpellation by low-energy electron diffraction (LEED) and Auger electron spectroscopy (AES) after emersion indicated that the surfaces had been reduced back to the wellordered, oxide-free metallic states; the quality of the AES spectra and LEED patterns, however, was less than ideal due to small amounts of base electrolyte remnant in the emersed layer.

In this Short Communication, we describe results from operando electrochemical scanning tunneling microscopy (EC-STM) of an as-received, commercially prepared $\mathrm{Cu}(100)$ singlecrystal electrode that had been exposed to atmospheric oxygen for an extended period. The present work is a more accurate representation of the first-time use of actual copper electrocatalysts. 


\section{EXPERIMENTAL}

A crystallographically oriented $\mathrm{Cu}(100)$ disk, $99.999 \%$ in purity, $1.0 \mathrm{~mm}$ in thickness, and $10 \mathrm{~mm}$ in diameter, was purchased commercially (Princeton Scientific Corp, Princeton, NJ). The crystal, which had been freely handled in ambient-atmosphere conditions for an unspecified period, was purposedly exposed to air for another seven days. It was then used for the EC-STM experiments, in deaerated 0.10 M KOH (Sigma-Aldrich, St. Louis, MO), without pretreatment other than sonication in acetone followed by copious rinses with MilliQ water (Millipore Corporation, Billerica, MA).

EC-STM was carried out with an Agilent 5500 microscope (Agilent Technologies, Santa Clara, CA) equipped with a three-electrode potentiostat. An electrochemical cell was customcrafted from Kel-F® (Emco Industrial Plastics, Inc.), fitted with a Pt counter and a Pt pseudoreference electrode calibrated against an SHE reference cell. The STM tips were prepared by an electrochemical etch of a $0.25 \mathrm{~mm}$ diameter tungsten wire (Sigma-Aldrich) in $1.0 \mathrm{M} \mathrm{KOH}$ at $c a$. $15 \mathrm{~V}$. All images were obtained with a high-resolution scanner in a constant-current mode without post-scan processes such as with high-pass filters. 


\section{RESULTS AND DISCUSSION}

Figure 1 shows a low-resolution $(500 \mathrm{~nm} \times 500 \mathrm{~nm})$ in situ STM image of the air-exposed $\mathrm{Cu}(100)$ electrode surface at the rest or open-circuit potential (OCP), $c a .0 .1 \mathrm{~V}$ vs. SHE, in $0.1 M$ $\mathrm{KOH}$. The existence of only narrow (high step-density) and topographically rounded terraces is easily discernible; the excessive step density, which is atypical of single-crystal surfaces, is due to the fact that thermal or electrochemical pretreatments had been carefully avoided. The terraces are completely covered with a highly disordered surface-oxide crust that could not be imaged at higher resolution. Operando EC-STM at potentials between $0.1 \mathrm{~V}$ and $-0.1 \mathrm{~V}$ did not reveal any changes in the image displayed in Figure 1.

The chemical nature of the air-oxidized electrode surface was examined by cyclic voltammetry. The dashed curve in Figure 2 represents the first voltammetric cycle, initially from the OCP in the direction of more negative potentials. Two cathodic peaks are observed, a minor one at $-0.32 \mathrm{~V}$ and a rather large, broad peak at $-0.80 \mathrm{~V}$. Neither of these two is present in subsequent (solid curve) scans. In the reverse, anodic-direction scan, only one peak appears at $0.03 \mathrm{~V}$. This anodic peak is also found in later current-potential cycles, along with a cathodic peak at $-0.38 \mathrm{~V}$. It is clear from Figure 2 that the steady-state anodic and cathodic peaks represent, respectively, the forward and reverse processes of the same interfacial redox reaction; in conformity to published studies $[7,8]$, the reaction is attributed to the kinetically irreversible $\mathrm{Cu}_{2} \mathrm{O}_{(\mathrm{s})} / \mathrm{Cu}_{(\mathrm{s})}$ monolayer-limited surface redox process. It thus appears that the small first-scan (dashed curve) cathodic peak in Figure 2 is a low-coverage $\mathrm{Cu}_{2} \mathrm{O}_{(\mathrm{s})}$-to- $2 \mathrm{Cu}_{(\mathrm{s})}$ reduction, with the shift in peak potential most likely due to its presence in the outer vicinity of the thick oxide crust.

It is evident in Figure 2, and in agreement with earlier work [7,8], that the fairly sizable cathodic peak centered at $-0.8 \mathrm{~V}$, can only be ascribed to the $\mathrm{CuO}_{(\mathrm{s})}-$ to- $-\mathrm{Cu}_{(\mathrm{s})}$ reduction. In controlled experiments on the anodic oxidation of $\mathrm{Cu}$ at potentials more positive than required for $2 \mathrm{Cu}_{(\mathrm{s})}-$ to- $-\mathrm{Cu}_{2} \mathrm{O}_{(\mathrm{s})}$ oxidation, it was found that the morphology of the $\mathrm{CuO}_{(\mathrm{s})}$-to- $-\mathrm{Cu}_{(\mathrm{s})}$ reduction 
peak was influenced by the thickness of the higher oxide film. However, the breadth of the $\mathrm{CuO}_{(\mathrm{s})}$-to- $\mathrm{Cu}_{(\mathrm{s})}$ peak in Figure 2, stretched from $-0.5 \mathrm{~V}$ to $-1.0 \mathrm{~V}$, is exceptional; other interfacial factors, undocumented at this time, are almost certainly in play.

The thickness of the surface oxide film, in terms of the number of monolayers of $\mathrm{CuO}$ and $\mathrm{Cu}_{2} \mathrm{O}$, was obtained from the Faradaic charges for the first-scan reduction peaks referenced against that for the steady-state $\mathrm{Cu}_{2} \mathrm{O}$ reduction; because the latter is surface-limited, by virtue of Faraday's Law, it defines the charge for one monolayer. The experimental data indicate 5 monolayers of $\mathrm{CuO}$ and 0.25 monolayer of $\mathrm{Cu}_{2} \mathrm{O}$.

Figure 3 shows a low-resolution $(500 \mathrm{~nm} \times 500 \mathrm{~nm})$ operando EC STM image at $-0.9 \mathrm{~V}$ after cathodic reduction of the $\mathrm{CuO}$ and $\mathrm{Cu}_{2} \mathrm{O}$ crust. It is most noteworthy that, compared to the image of the oxided electrode in Figure 1, the surface is now constituted of wider and flatter terraces. It is discernible that the density of step-lines has decreased; its persistence is due to the absence of thermal pretreatment prior to the experiments.

The high-resolution ( $5 \mathrm{~nm} \times 5 \mathrm{~nm}$ ), atom-resolved image of the oxide-free terraces is displayed in Figure 4. It reveals a square $(1 \times 1)$ lattice. While the terraces are not particularly wide, the atomic arrangement within a given terrace is highly ordered. The interatomic distance was measured to be $0.27 \pm 0.01 \mathrm{~nm}$, a value identical to that for a pristine, oxide-free square $\mathrm{Cu}(100)$ net. The regeneration of a clean and well-ordered $\mathrm{Cu}(100)-(1 \times 1)$ surface by cathodic reduction of the surface oxide is thus established. 


\section{CONCLUSIONS}

The cathodic regeneration of a clean and well-ordered $\mathrm{Cu}(100)$ electrode from a disordered air-oxided surface, has been studied by operando electrochemical scanning tunneling microscopy. It was found that a commercially oriented $\mathrm{Cu}(100)$ sample, previously exposed to ambient air for over a week, consisted of narrow (high step-density) terraces encrusted with highly disordered oxides. Cyclic voltammetry and coulometry showed that the surface oxides were made up of five monolayers of $\mathrm{CuO}$ and quarter of a monolayer of $\mathrm{Cu}_{2} \mathrm{O}$. Upon complete cathodic reduction of the oxide film, the surface was observed to have reverted to a single-crystalline $\mathrm{Cu}(100)-(1 \times 1)$ structure. It may thus be inferred that, under conditions typical of electrochemical $\mathrm{CO}_{2}$ reduction, the copper elecrocatalyst would exist as a zerovalent metal. 


\section{ACKNOWLEDGMENTS}

This material is based upon work performed by the Joint Center for Artificial

Photosynthesis, a DOE Energy Innovation Hub, supported through the Office of Science of the U.S. Department of Energy under Award No. DE-SC0004993. 


\section{REFERENCES}

1. Y. Hori, H. Wakebe, T. Tsukamoto, O. Koga, Surf. Sci. 335 (1995) 258.

2. J. Christophe, Th. Doneux and C. Buess-Herman, Electrocatal. 3 (2012) 139.

3. K. P. Kuhl, E. R. Cave, D. N. Abram and T. F. Jaramillo, Energy Environ. Sci. 5 (2012) 7050.

4. G. Ertl. Surf. Sci. 7 (1967) 309.

5. R. N. Lee and H. E. Farnsworth. Surf. Sci. 3 (1965) 461-479.

6. J. H. Baricuatro, C. B. Ehlers, K. D. Cummins, M. P. Soriaga, J. L. Stickney and Y.-G. Kim. J. Electroanal. Chem. 716 (2014) 101.

7. C-H. Pyun and S-M. Park. J. Electrochem. Soc. 133 (1986) 2024.

8. L. D. Burke, M. J. G. Ahern and T. G. Ryan. J. Electrochem. Soc. 137 (1990) 553. 


\section{FIGURES}

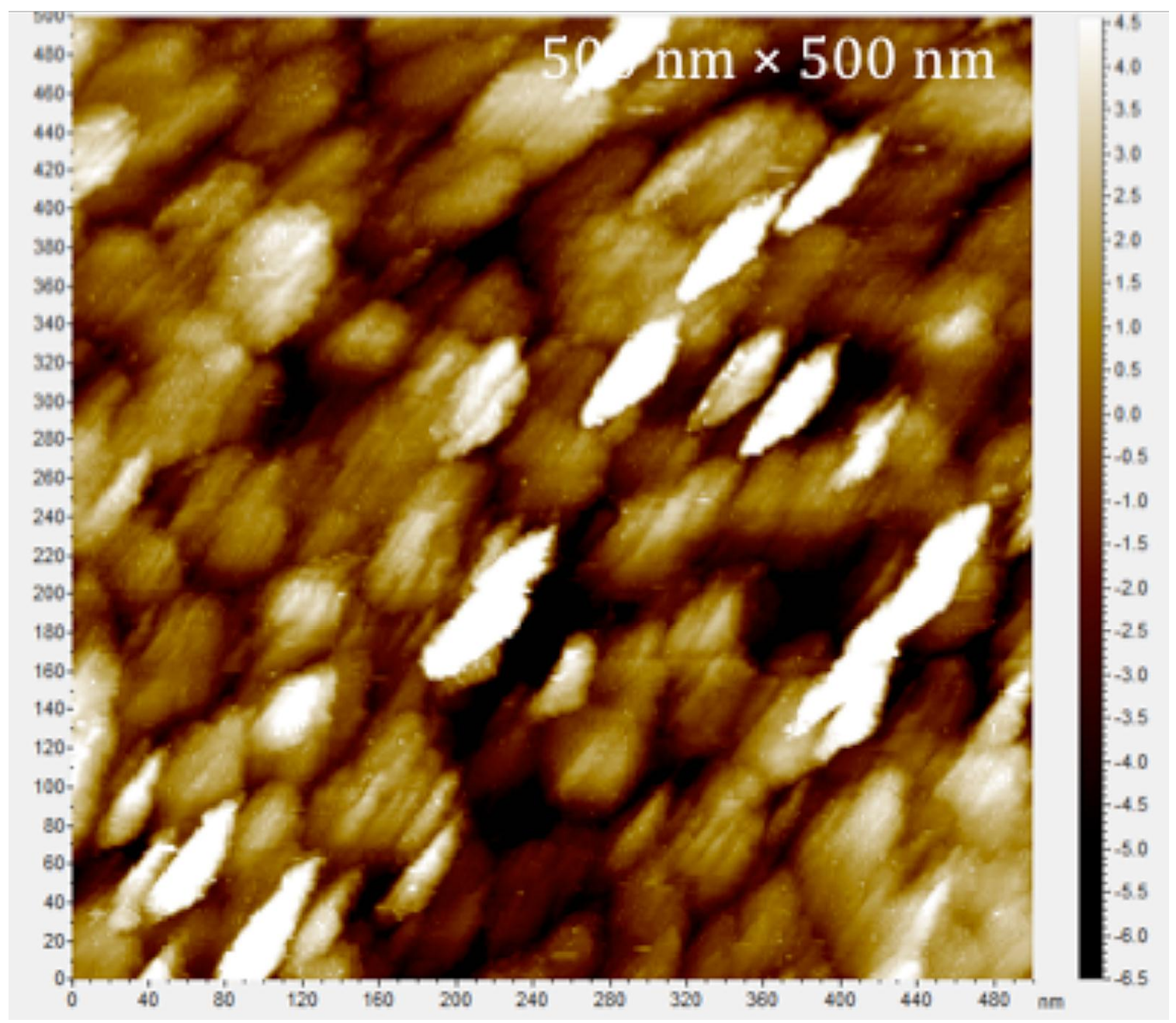

Figure 1. Low-resolution in situ STM image of the air-oxidized $\mathrm{Cu}(100)$ electrode surface at the open-circuit potential in $0.1 \mathrm{M} \mathrm{KOH}$. Experimental parameters: Bias voltage $=250 \mathrm{mV}$; tunneling current, $2 \mathrm{nA}$. 
Voltammetry of Oxided and Cathodically Regenerated $\mathrm{Cu}(100)$

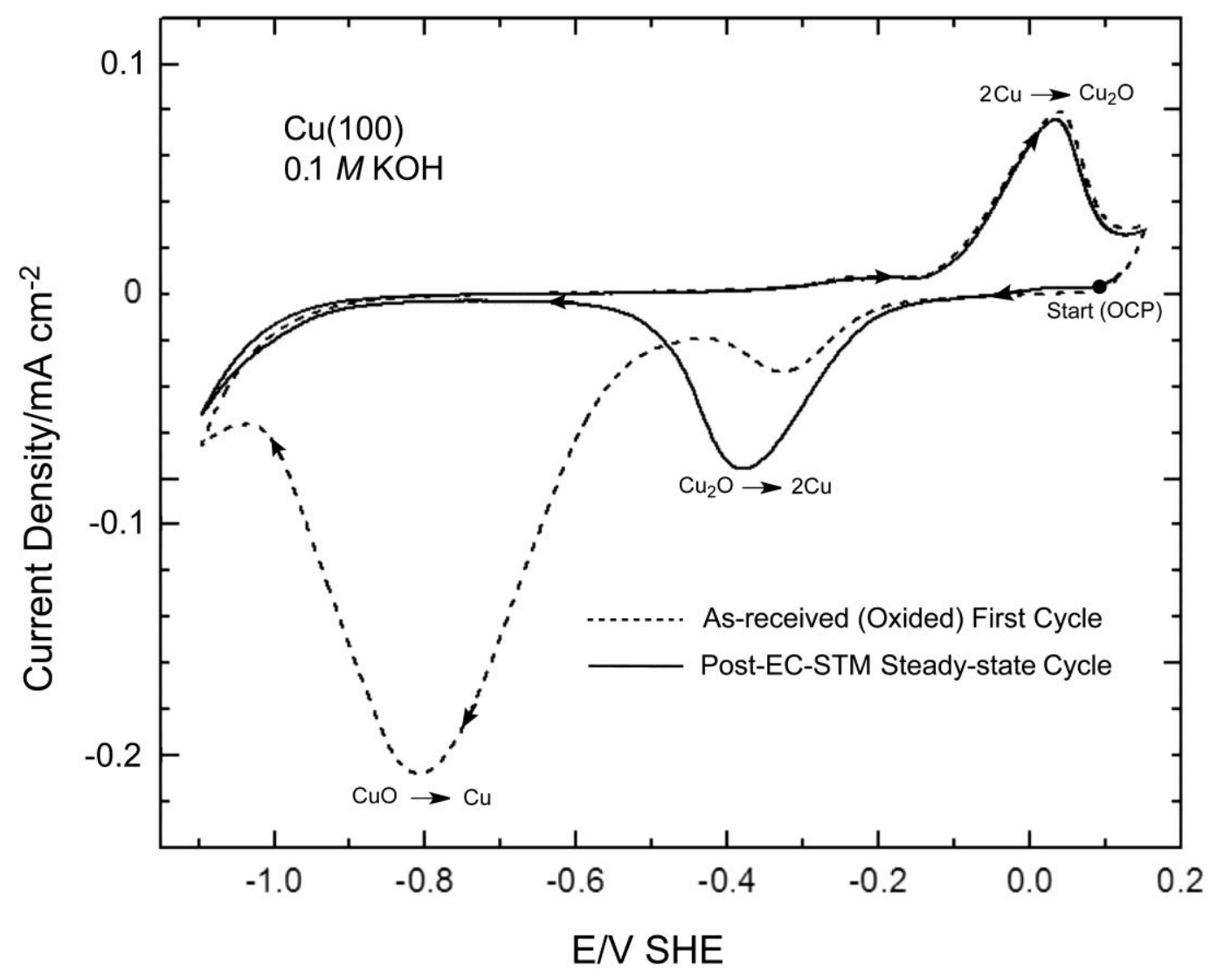

Figure 2. Cyclic voltammetric curves for the oxided (dashed curve: first scan) and cathodically regenerated (solid curve: steady-state scan) $\mathrm{Cu}(100)$ in $0.1 M \mathrm{KOH}$. The potential scan rate was $50 \mathrm{mV} \mathrm{sec}^{-1}$; the geometric area of the electrode was $1.84 \mathrm{~cm}^{2}$. 


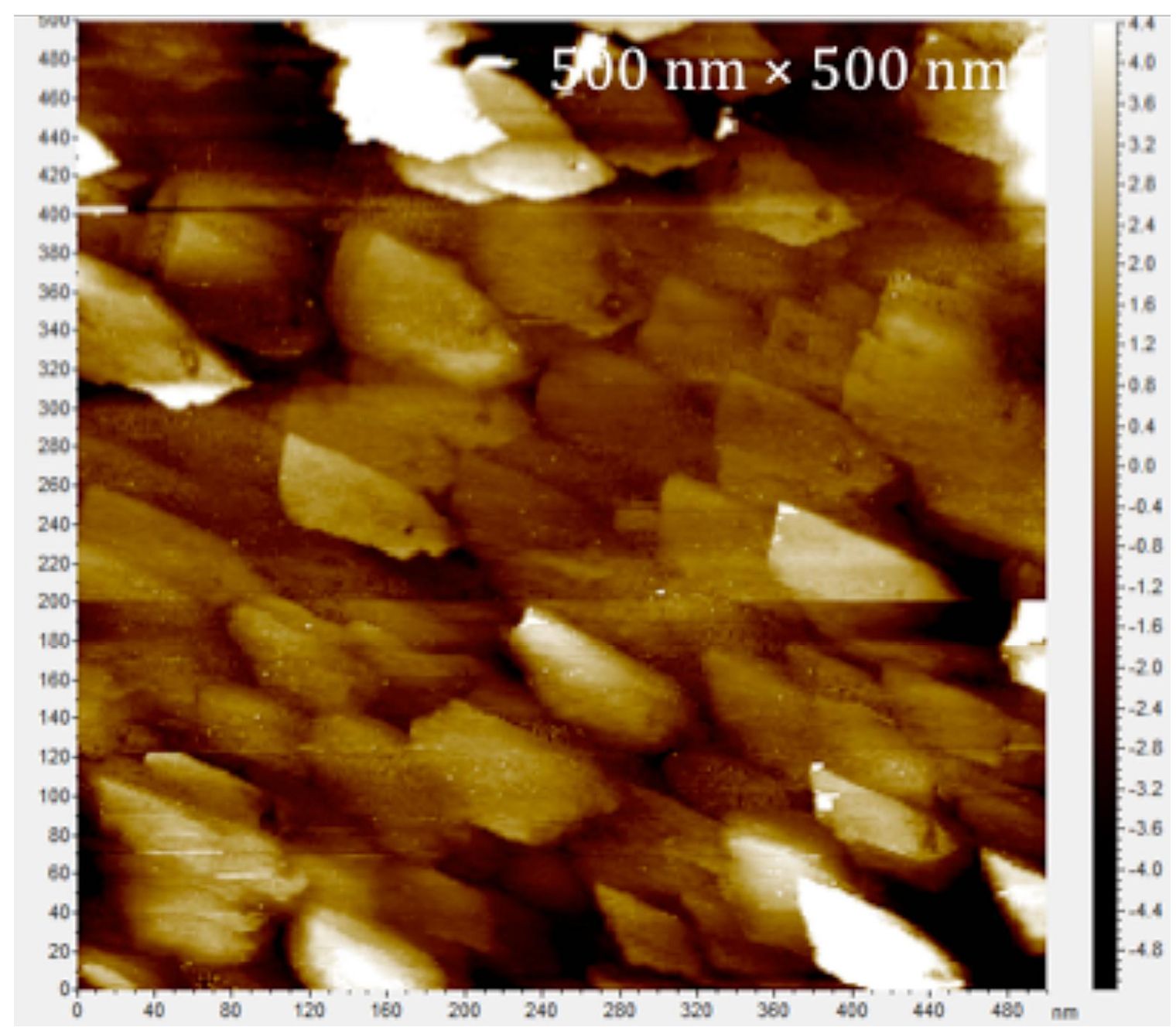

Figure 3. Low-resolution operando STM image, at $-0.9 \mathrm{~V}$ in $0.1 M \mathrm{KOH}$, of the cathodically regenerated $\mathrm{Cu}(100)$ electrode surface. Experimental parameters: Bias voltage $=-120 \mathrm{mV}$; tunneling current, $2 \mathrm{nA}$. 


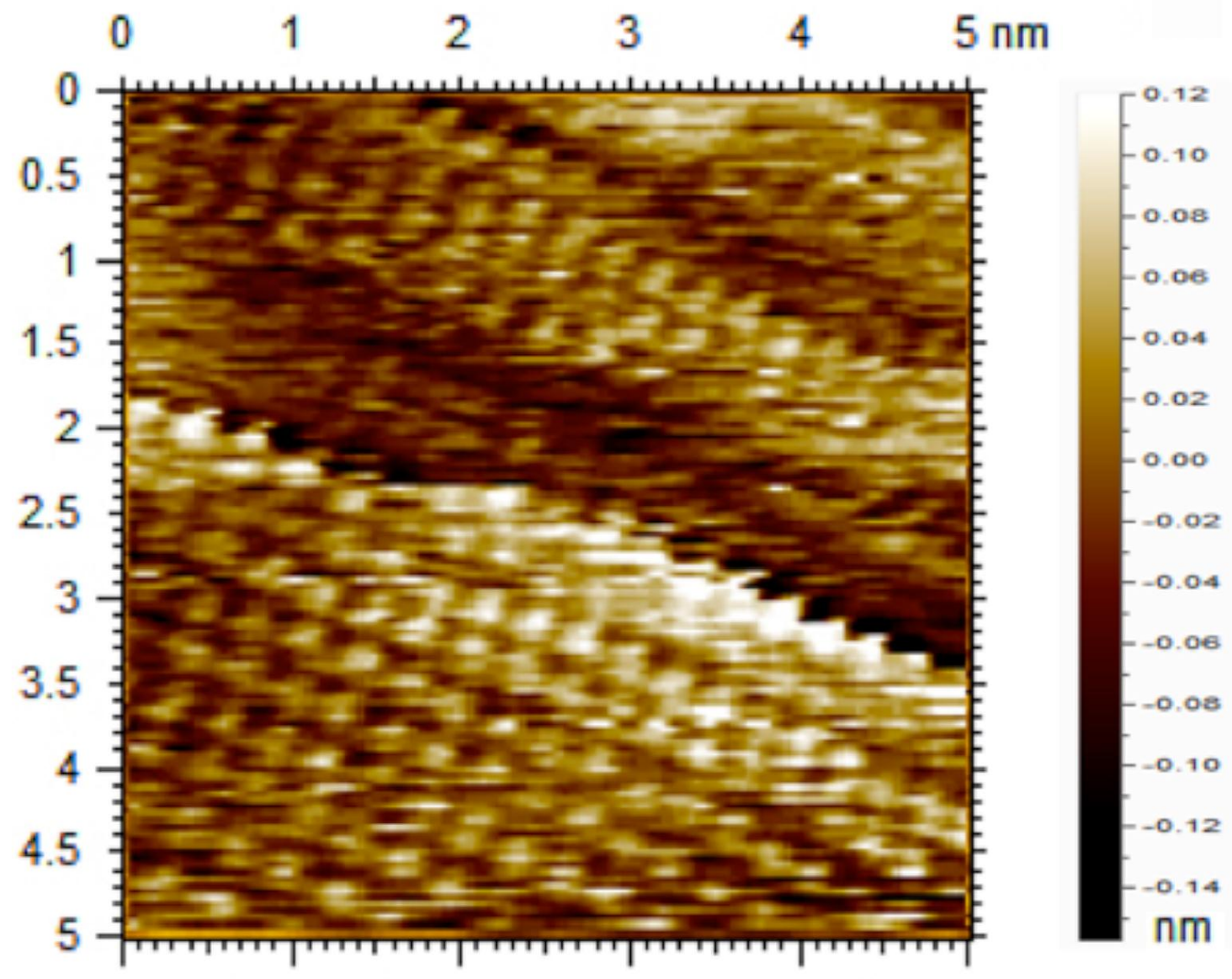

Figure 4. High-resolution operando STM image, at $-0.9 \mathrm{~V}$ in $0.1 M \mathrm{KOH}$, of the cathodically regenerated $\mathrm{Cu}(100)$ electrode surface. Experimental parameters: Bias voltage $=-120 \mathrm{mV}$; tunneling current, $5 \mathrm{nA}$. 